\title{
PENGARUH PENGGUNAAN AFO FLEKSIBEL TERHADAP KESEIMBANGAN DINAMIS PADA HEMIPARETIC CEREBROVASCULAR ACCIDENT (CVA)
}

\author{
Nur Rachmat, Agus Seto Nugroho, M Syafii \\ Kementerian Kesehatan Politeknik Kesehatan Surakarta Jurusan Ortotik Prostetik \\ Diterima : 4 Oktober 2018, Disetujui : 10 Oktober 2018 \\ Email : nurrachmat@gmail.com
}

\begin{abstract}
Background: Stroke or Cerebrovascular Accident (CVA) is a primary neurologic problem in the United States and in the World. There are approximately 2 million people surviving from strokes that have a disability of $40 \%$ need help in daily activities (Brunener \& Suddarth, 2002). The restoration of the functioning of the limbs and the ability to move within a community is a top priority for individual adoption after experiencing CVA. Ankle Foot Orthosis (AFO) can be used by someone with a CVA hemiparetic to help restrain ambulation abilities. AFO can prevent drop foot, controls the ankle in the coronal and sagittal areas during standing and walking and improves the stability of the knee during ambulation. Method: This research use cross sectional study method to find out what happened now by using correlative design design research. The researcher discusses the strength of the relationship between variables that is dynamic balance in drop foot because CVA, when using AFO Flexible. This data is obtained from direct measurement of dynamic balance of Flexible AFO users using Time up and go Test. Results :Differences in the effect of AFO on the dynamic balance of Hemiaretic Cerebrovascular Accident (CVA) patients in the intervention and control group. The results showed the average dynamic balance of hemiaretic cerebrovascular accident patients in the intervention group (28.20) while the mean equilibrium was maintained in the control group (12.80). The result of statistical test with man whitney showed $p$ value 0,000 <0,05 so there was difference of influence of AFO use to dynamic balance of Hemiaretic Cerebrovascular Accident (CVA) patient in intervention group and control group. This means that the more frequently the patient uses AFO in daily activities it can improve the optimal dynamic balance and can perform activities independently. Conclusion: There is a difference in the effect of AFO on the dynamic balance of Hemiaretic Cerebrovascular Accident (CVA) patients in the intervention and control group with p value 0,000<0.05.
\end{abstract}

Keyword: Ankle Foot Orthosis, Hemiaretic Cerebrovascular Accident, Dynamic Balance

\section{PENDAHULUAN}

Cedera Cerebrovaskular (CVA) adalah masalah neurlogik primer di Amerika Serikat dan di Dunia. Meskipun upaya pencegahan telah menimbulkan penurunan pada kejadian beberapa tahun terakhir, Stroke peringkat ketiga penyebab kematian, dengan laju mortalitas $18 \%$ sampai $37 \%$ untuk stroke pertama dan sebesar $62 \%$ untuk stroke selanjutnya. Terdapat kira-kira 2 juta orang pertahan hidup dari stroke yang mempunyai 
beberapa kecacatan dari angka $40 \%$ memerlukan bantuan dalam aktifitas sehari-hari (Brunener\&Suddarth, 2002). Stroke merupakan penyakit sistem persarafan yang paling sering di jumpai kira-kira 200.000 kematian dan 200.000 orang dengan gejala sisa akibat stroke pada setiap umur, tetapi yang paling sering pada usia 75-85 tahun. Pada setiap bagian ini terminologi CVA akan dipakai sebagai istilah umum. Banyak ahli saraf dan bedah saraf menyatakan penyebab CVA paling sering adalah Trombosis, emboli, dan hemoragik. Stroke dapat didahului oleh beberapa faktor pencetus dan sering kali yang berhubungan dengan penyakit kronis yang menyebabkan misalnya penyakit vaskular termasuk penyakit jantung, hipertensi, diabetes, obesitas, kolesterol, merokok, stress, dan gaya hidup (Muttaqin, 2008).

World Health Organisation (WHO) menyatakan bahwa sekitar 5, 5 juta orang di dunia meninggal akibat stroke pada tahun 2002 (Juniarti, 2008). Konferensi Stroke Internasional tahun 2008 yang diadakan di Wina, Austria, mengungkapkan bahwa jumlah kasus stroke di kawasan Asia terus meningkat (Jurnal Stroke, 2010). Projodisastro (2009) dalam Juniarti (2008) memperkirakan penyakit jantung dan stroke akan menjadi penyebab utama kematian di dunia pada tahun 2020. Selain itu, WHO (2004) dalam Aziz et al (2008) memprediksi bahwa jumlah kasus stroke akan meningkat sehubungan dengan peningkatan trend dalam populasi lanjut usia di seluruh dunia.

Data stroke yang dikeluarkan oleh Yayasan Stroke Indonesia menyatakan bahwa penderita stroke di Indonesia jumlahnya terus meningkat dari tahun ke tahun (Jurnal Stroke, 2010). Berdasarkan penelitian Riset Kesehatan Dasar tahun

2007 di 33 provinsi dan 440 kabupaten di Indonesia diperoleh hasil bahwa penyakit stroke merupakan pembunuh utama di kalangan penduduk perkotaan (Riskesdas, 2007). Secara kasar, setiap hari ada dua orang Indonesia mengalami serangan stroke.

Dalam beberapa pembelajaran mengenai Ankle Foor Orthosis ( AFO ) menunjukan bahwa AFO Fleksibel mempunya indikasi digunakan untuk drop foot dengan spasticity sedang, serta kontra indikasi berupa medio-lateral insstability, odema, serta knee hyperextensi. AFO Fleksibel mempunyai keuntungan berupa pergerakan pada ankle masih memungkinkan terjadi, Praktis untuk dipakai, kosmetiknya bagus serta sesuai dengan sepatu yang aman digunakan.

\section{METODE PENELITIAN}

Jenis penelitian ini adalah Quasy Experimental dengan menggunakan pre and post test with control design.

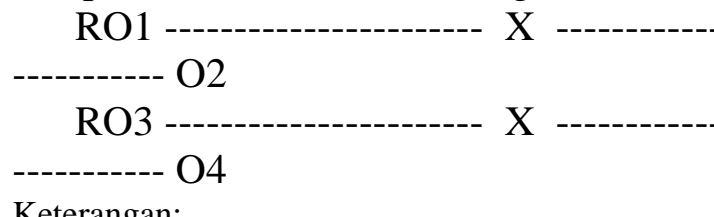

Keterangan:

$\mathrm{O} 1=$ Kelompok Pre Test pada penderita CVA tanpa menggunakan AFO

$\mathrm{O} 2$ = Kelompok Post Test pada penderita CVA tanpa menggunakan AFO Fleksibel O3 = Kelompok Pre Test pada penderita CVA menggunakan AFO

$\mathrm{O} 4=$ Kelompok Post Test pada penderita CVA menggunakan AFO Fleksibel

Penelitian ini dilakukan di Klinik APOC Boyolali pada bulan Januari sampai dengan April 2017. 
Variabel Penelitian

1. Variabel independen

Pada penelitian ini variabel independen adalah penggunaan AFO Fleksibel pada pasien Hemiparetic Cerebrovascular Accident (CVA)

2. Variabel dependen

Pada penelitian ini variabel dependen adalah keseimbangan dinamis saat berjalan.

\section{Definisi Operasional}

1. Ankle Foot Orthosis adalah jenis orthosis anggota gerak bawah yang dapat digunakan untuk mengkoreksi, memberikan supporting serta mencegah terjadinya kecacatan pada regio foot dan ankle.

2. Ankle Foot Orthosis Fleksibel adalah jenis orthosis anggota gerak bawah yang dapat digunakan untuk mengkoreksi,memberikan

supporting serta mencegah terjadinya kecacatan pada regio foot dan ankle dengan desain fleksibel sehingga membatasi terjadinya gerakan plantarfleksi pada ankle dan foot dan memungkinkan terjadi gerakan dorsal fleksi pada fase stance phase

3. TUG Test adalah test keseimbangan dinamis untuk mengukur kecepatan reaksi terhadap aktivitas yang memerlukan keseimbangan. Alat yang digunakan adalah sebuah kursi dengan sandaran dan penyangga lengan, stopwatch dan dinding (Wall et al, 2000).
Jumlah dan Cara Penetapan Sampel

1. Populasi Sampel dalam penelitian ini antara lain:

Populasi penelitian adalah pasien pria dan wanita dengan hemiparesis cerebrovascular accident (CVA). Kriteria inklusi adalah keadaan pada subyek penelitian, yang berhubungan dengan kondisi yang diteliti, meliputi (1) mempunyai skala ashworth kurang dari 2, (2) Mampu berjalan pada jarak $10 \mathrm{~m}$ tanpa menggunakan AFO tetapi dengan menggunakan alat bantu mobilitas seperti tongkat / kruk, (3) Mampu memahami instruksi yang di berikan.

Kriteria eksklusi adalah keadaan pada subyek penelitian, yang tidak berhubungan dengan kondisi yang diteliti, namun dapat menjadi kendala penelitian, meliputi (1) Mempunyai riwayat gangguan neurologic maupun orthopedic yg signifikan, (2) Terdapat deformitas berupa kontraktur plantar flexion ankle.(3) Tidak mampu memahami instruksi yang di berikan.

2. Sampel.

Sampel diambil dengan Purposive Sampling, terdapat 20 responden sebagai kelompok intervensi dan 20 responden sebagai kelompok perlakuan yang memenuhi persyaratan dan bersedia menanda tangani Lembar Persetujuan Subyek (letter of consent), terdiri dari pria dan wanita.

Instrumen penelitian yang di gunakan untuk mengetahui keseimbangan dinamis subyek adalah Time Up and Time Go Test. TUG Test adalah adalah test keseimbangan dinamis untuk mengukur kecepatan reaksi terhadap aktivitas yang memerlukan keseimbangan. Alat yang digunakan adalah sebuah kursi dengan sandaran dan penyangga lengan, stopwach dan dinding 
(wall at al, 2000)

Cara dan Metode Analisa Data, langkah pertama di awali dengan persiapan ijin melakukan persetujuan terhadap responden dan blangko pengambilan data. Lalu peneliti mulai pelaksanaan pengukuran semua subyek yang masuk dalam criteria inklusi, diukur keseimbangannya dengan Time Up and Go test. Alat - alat yang diperlukan dalam pelaksanaan test antara lain : kursi dengan sandaran dan penyangga lengan, stopwatch dan dinding. Prosedur test dijelaskan seperti berikut : posisi awal subyek duduk bersandar pada kursi dengan lengan berada pada penyangga lengan kursi, subyek mengenakan AFO Fleksibel yang biasa dipakai. Pada saat peneliti member aba - aba "mulai" subyek berdiri dari kursi, boleh menggunakan tangan untuk mendorong berdiri jika subyek menghendaki. Subyek terus berjalan sesuai dengan kemampuannya menempuh jarak 3 meter menuju ke dinding, kemudian berbalik tanpa menyentuh dinding dan berjalan kembali menuju kursi. Sesampainya didepan kursi subyek berbalik dan duduk kembali bersandar. Waktu dihitung seak aba - aba "mulai" sampai subyek duduk besandar kembali. Test ini tidak diperbolehkan mencoba atau berlatih terlebih dahulu (Setiawan, 2009).

Data hasil penelitian yang di dapat akan diolah dengan bantuan program SPSS. Jika data terdistribusi normal dengan nilai $\mathrm{p}>0,05$ maka menggunakan uji parametrik, sedangkan jika data terdistribusi tidak nornal dengan nilai $\mathrm{p}<$ 0,05 maka menggunakan uji non parametric. Uji hipotesis untuk mengetahui pengaruh penggunaan AFO terhadap keseimbangan dinamis pada kelompok intervensi dan kontrol sebelum dan setelah perlakuan menggunakan paired sample t-test jika data normal dan menggunakan uji wilcoxon jika data tidak normal. Dasar pengambilan keputusan apabila $\mathrm{p}<0,05$ berarti ada pengaruh yang bermakna antara variable independen dan dependen, sehingga dapat disimpulkan bahwa hipotesis nol (H0) ditolak dan hipotesis alternatif (Ha) diterima.

Untuk mengetahui perbedaan penggunaan AFO terhadap keseimbangan dinamis pada kelompok intervensi dan kontrol menggunakan uji independent sample t-test jika data normal dan menggunakan uji man whitney jika data terdistribusi tidak normal.

\section{HASIL PENELITIAN}

\section{Karakteristik Sampel Penelitian}

Hasil karakteristik sampel penelitian data kontinu meliputi waktu tempuh dan keseimbangan dinamis pada pasien dengan hemiparesis cerebrovascular accident (CVA) pada kelompok kontrol dan kelompok intervensi dapat dilihat pada tabel 4.1

Tabel 1. Usia Sampel Kelompok Crutch dan Kelompok Prosthesis

\begin{tabular}{|c|c|c|c|c|}
\hline \multirow[t]{2}{*}{ Variabel } & \multicolumn{2}{|c|}{$\begin{array}{c}\text { Waktu } \\
\text { Tempuh } \\
\text { Kel. Kontrol }\end{array}$} & \multicolumn{2}{|c|}{$\begin{array}{c}\text { Keseimbangan } \\
\text { Dinamis } \\
\text { Kel. Kontrol }\end{array}$} \\
\hline & Pretest & Postest & Pretest & Postest \\
\hline $\mathrm{N}$ & 20 & 20 & 20 & 20 \\
\hline Min & 25,3 & 25,3 & 0,34 & 0,34 \\
\hline Max & 29,7 & 29,7 & 0,39 & 0,39 \\
\hline Mean & 27,7 & 27,6 & 0,36 & 0,36 \\
\hline SD & 1,39 & 1,36 & 0,19 & 0,19 \\
\hline \multirow[t]{2}{*}{ Variabel } & \multicolumn{2}{|c|}{$\begin{array}{c}\text { Waktu } \\
\text { Tempuh } \\
\text { Kel. Perlakuan } \\
\end{array}$} & \multicolumn{2}{|c|}{$\begin{array}{c}\text { Keseimbangan } \\
\text { Dinamis } \\
\text { Kel. Perlakuan }\end{array}$} \\
\hline & Pretest & Postest & Pretest & Postet \\
\hline $\mathrm{N}$ & 20 & 20 & 20 & 20 \\
\hline Min & 23,9 & 21,9 & 0,33 & 0,35 \\
\hline Max & 30,3 & 28,9 & 0,42 & 0,46 \\
\hline Mean & 26,4 & 24,5 & 0,38 & 0,41 \\
\hline SD & 1,90 & 1,95 & 0,27 & 0,31 \\
\hline
\end{tabular}




\section{Pengaruh penggunaan AFO terhadap keseimbangan dinamis pada Hemiaretic Cerebrovascular Accident (CVA) sebelum dan setelah perlakuan pada kelompok intervensi}

Hasil uji normalitas dengan shapiro wilk diketahui bahwa pada kelompok intervensi diperoleh $p$ value keseimbangan pretest sebesar 0,303 > 0,05 sehingga data terdistribusi normal dan $p$ value keseimbangan postest sebesar $0,383>0,05$ sehingga data terdistribusi normal. Karena kedua kelompok perlakuan tersebut data terdistribusi normal maka digunakan statistik parametrik yaitu uji paired sample t-test. Hasil penelitian pengaruh penggunaan AFO terhadap keseimbangan dinamis pada Hemiaretic Cerebrovascular Accident (CVA) sebelum dan setelah perlakuan pada kelompok intervensi dapat dilihat pada tabel berikut :

Tabel 2. Pengaruh penggunaan AFO terhadap keseimbangan dinamis pada pasien Hemiaretic Cerebrovascular Accident (CVA) kelompok intervensi

\begin{tabular}{ccccc}
\hline Variabel & Perlakuan & Mean & $\mathrm{t}$ & $\begin{array}{c}p \\
\text { value }\end{array}$ \\
\hline $\begin{array}{c}\text { Keseimbangan } \\
\text { Dinamis }\end{array}$ & Pretest & 0,38 & $-11,59$ & 0,000 \\
\hline
\end{tabular}

Hasil penelitian menunjukkan rata-

rata keseimbangan dinamis pasien hemiaretic cerebrovascular accident pada kelompok intervensi nilai pretest $(0,38)$ sedangkan rata-rata keseimbangan dimanis postest $(0,41)$. Hasil uji statistik dengan paired sample t-test menunjukkan $p$ value $0,000<0,05$ sehingga terdapat pengaruh penggunaan AFO terhadap keseimbangan dinamis pada pasien Hemiaretic Cerebrovascular Accident (CVA) kelompok intervensi.

\section{Pengaruh penggunaan AFO terhadap keseimbangan dinamis pada Hemiaretic Cerebrovascular Accident (CVA) pada kelompok kontrol}

Hasil uji normalitas dengan shapiro wilk diketahui bahwa pada kelompok kontrol diperoleh $p$ value keseimbangan pretest sebesar 0,032 < 0,05 sehingga data terdistribusi tidak normal dan $p$ value keseimbangan postest sebesar $0,038<0,05$ sehingga data terdistribusi tidak normal. Karena kedua kelompok perlakuan tersebut data terdistribusi tidak normal maka digunakan statistik non parametrik yaitu uji wilcoxon. Hasil penelitian pengaruh penggunaan AFO terhadap keseimbangan dinamis pada Hemiaretic Cerebrovascular Accident (CVA) pada kelompok kontrol dapat dilihat pada tabel berikut :

Tabel 3. Pengaruh penggunaan AFO terhadap keseimbangan dinamis pada pasien Hemiaretic Cerebrovascular Accident (CVA) kelompok kontrol

\begin{tabular}{ccccc}
\hline Variabel & Kontrol & Mean & $\mathrm{Z}$ & $\begin{array}{c}p \\
\text { value }\end{array}$ \\
\hline $\begin{array}{c}\text { Keseimbangan } \\
\text { Dinamis }\end{array}$ & Pretest & 0,00 & - & 0,066 \\
\hline
\end{tabular}

Hasil penelitian menunjukkan ratarata keseimbangan dinamis pasien hemiaretic cerebrovascular accident pada kelompok kontrol nilai pretest $(0,00)$ sedangkan rata-rata keseimbangan dimanis postest $(2,50)$. Hasil uji statistik dengan wilcoxon menunjukkan $p$ value $0,066>0,05$ sehingga tidak terdapat pengaruh penggunaan AFO terhadap keseimbangan dinamis pasien Hemiaretic Cerebrovascular Accident (CVA) pada kelompok kontrol. 
4. Perbedaan Pengaruh penggunaan AFO terhadap keseimbangan dinamis pada Hemiaretic Cerebrovascular Accident (CVA) pada kelompok intervensi dan kelompok kontrol

Hasil uji normalitas dengan shapiro wilk diketahui bahwa pada kelompok intervensi diperoleh $p$ value keseimbangan postest sebesar 0,383 > 0,05 sehingga data terdistribusi normal dan pada kelompok kontrol $p$ value keseimbangan postest sebesar 0,038 < 0,05 sehingga data terdistribusi tidak normal. Karena pada kelompok perlakuan dan kelompok kontrol terdapat data terdistribusi tidak normal maka digunakan statistik non parametrik yaitu uji man whitney. Hasil penelitian perbedaan pengaruh penggunaan AFO terhadap keseimbangan dinamis pada Hemiaretic Cerebrovascular Accident (CVA) pada kelompok intervensi dan kelompok kontrol dapat dilihat pada tabel berikut :

Tabel 4. Perbedaan Pengaruh Penggunaan Afo Terhadap Keseimbangan Dinamis Pasien Hemiaretic Cerebrovascular Accident (CVA) Kelompok Intervensi Dan Kelompok Kontrol

\begin{tabular}{cllll}
\hline Variabel & Perlakuan & Mean & $\mathrm{Z}$ & $\begin{array}{c}p \\
\text { value }\end{array}$ \\
\hline $\begin{array}{c}\text { Keseimbangan } \\
\text { Dinamis }\end{array}$ & $\begin{array}{l}\text { Kel. } \\
\text { Intervensi }\end{array}$ & 28,20 & $-4,17$ & 0,000 \\
& Kel. Kontrol & 12,80 & & \\
\hline
\end{tabular}

Hasil penelitian menunjukkan rata-

rata keseimbangan dinamis pasien hemiaretic cerebrovascular accident pada kelompok intervensi $(28,20)$ sedangkan rata-rata keseimbangan dimanis pada kelompok kontrol $(12,80)$. Hasil uji statistik dengan man whitney menunjukkan $p$ value $0,000<0,05$ sehingga terdapat perbedaan pengaruh penggunaan AFO terhadap keseimbangan dinamis pasien Hemiaretic Cerebrovascular Accident (CVA) pada kelompok intervensi dan kelompok kontrol.

\section{PEMBAHASAN}

Hasil penelitian dengan paired sample t-test menunjukkan $p$ value 0,000 $<0,05$ sehingga terdapat pengaruh penggunaan AFO terhadap keseimbangan dinamis pada pasien Hemiaretic Cerebrovascular Accident (CVA) kelompok intervensi hal ini berarti bahwa dengan pemberian penopang pada regio ankle dan foot dengan menggunakan orthosis berupa AFO tersebut maka akan dapat mencegah terjadinya drop foot pada saat seseorang dengan hemiparesis cerebrovascular accident sehingga penyimpangan keseimbangan yang terjadi dapat di minimalisir.

Hasil penelitian dengan wilcoxon menunjukkan $p$ value $0,066>0,05$ sehingga tidak terdapat pengaruh penggunaan AFO terhadap keseimbangan dinamis pasien Hemiaretic Cerebrovascular Accident (CVA) pada kelompok kontrol. Dimana permasalahan utama pada penderita hemiparetic cerebrovascular accident ( CVA) adalah terjadinya kelemahan pada sebagian anggota gerak baik anggota gerak atas maupun anggota gerak bawah, pada anggota gerak bawah khususnya regio ankle dan foot biasanya terjadi drop foot, hal ini dapat mempengaruhi keseimbangan dari pasien tersebut, dimana pada saat fase mengayun pada telapak kaki pasien tersebut tidak mampu melakukan gerakan dorsal fleksi sehingga dalam berjalan pasien dengan hemiparegic cerebrovascular accident akan menimbulkan pinyimpangan keseimbangan yang dapat berupa 
abducted gait maupun circumduction gait. Sehingga apabila tidak diberikan alat bantu (ortosis) maka tidak akan bisa mengubah keseimbangan pasien.

Hasil penelitian menunjukkan ratarata keseimbangan dinamis pasien hemiaretic cerebrovascular accident pada kelompok intervensi $(28,20)$ sedangkan rata-rata keseimbangan dimanis pada kelompok kontrol $(12,80)$. Hasil uji statistik dengan man whitney menunjukkan $p$ value $0,000<0,05$ sehingga terdapat perbedaan pengaruh penggunaan AFO terhadap keseimbangan dinamis pasien Hemiaretic Cerebrovascular Accident (CVA) pada kelompok intervensi dan kelompok kontrol. Hal ini berarti bahwa semakin sering pasien menggunakan AFO dalam aktivitas sehari-hari maka dapat meningkatkan keseimbangan dinamis secara optimal dan dapat melakukan aktivitas secara mandiri.

\section{KESIMPULAN DAN SARAN Kesimpulan}

1. Terdapat pengaruh penggunaan AFO terhadap keseimbangan dinamis pada pasien Hemiaretic Cerebrovascular Accident (CVA) kelompok intervensi dengan $p$ value $0,000<0,05$.

2. Tidak terdapat pengaruh penggunaan AFO terhadap keseimbangan dinamis pasien Hemiaretic Cerebrovascular Accident (CVA) pada kelompok kontrol dengan $p$ value $0,066>0,05$.

3. Terdapat perbedaan pengaruh penggunaan AFO terhadap keseimbangan dinamis pasien Hemiaretic Cerebrovascular Accident (CVA) pada kelompok intervensi dan kelompok kontrol dengan $p$ value $0,000<0,05$.

Saran

Bagi pasien pasien Hemiaretic Cerebrovascular Accident (CVA) sebaiknya menggunakan Ankle Foot Orthosis dalam melakukan aktivitas secara fungsional agar keseimbangan dinamis meningkat terutama saat berjalan.

\section{DAFTAR RUJUKAN}

Bethesda stroke center. Stroke di Yogyakarta.2007. availeble at: http://www.strokebethesda.com/co ntent/view//233/42/ (diposkan tgl 23 September 2009)

CSPO Lecturers (2010); Lower Extremity Orthotics Manual; Foot/Ankle Orthotics (FO/AFO), Cambodian School of Prosthetics\&Orthorics Phnom Penh, Cambodia.

Jurnal Stroke ( 2010 ). Data Penderita Stroke di Indonesia. Avilable at : http // Www.datastroke.blogspot.com/2010 Diposkan 21 Maret 2010)

Feigin V ( 2007 ). Stroke. Panduan Bergmabar Tentang Pencegahan \& Pemulihan Stroke. Jakarta. PT. Bhuana Ilmu Populer pp 9-20

Price S.A dan Wilson Lorriane M.C. (2006). Patofisologi Clinical Concepsts of Desiase Process. Edisi 6 Vol 2 Alih bahasa Brahm. U. EGC.Jakarta

Muttaqin Arif 2008. Buku Ajar Asuhan Keperawatan Klien Dengan Gangguan Sistem Persyarafan. Jakarta : Salemba Medica

Smeltzer C. Suzanne, Brenner \& Suddarth. 2002. Buku Ajar Keperawatan Medical Bedah. EGC.Jakarta 
88 Jurnal Keterapian Fisik, Volume 3, No 2,November 2018, hlm 58-111

Smeltzer C. Suzanne.dkk.2001. Buku Ajar Keperawatan Medical Bedah (Edisi 8). Jakarta : EGC

Van Excel.dkk (2005). Melanjutkan Hidup Pasca Stroke. Diakses pada tanggal 8 Agustus 2015 dari http:// www.bethesdastrokecenter.com

WHO. 2010. World Health Statistic 2009. France. Available at : http // www.who.int/helthinfo/statistic/pr ograme/en/index.html

Yuniarti T.2008. Ensiklopedia Tanaman Obat Tradisional. Cetakan pertama.Yogyakarta.medpress 